\title{
Sala de Espera: uma Experiência no Serviço de Onco- Hematologia Pediátrica
}

\author{
Urbano, Adna Santos; Monteiro, Rita Mara da Cruz; Cristófani, Lílian Maria; Cury, \\ Marina Rachel Graminha; Nabarrete, Juliana Moura; Andrade, Bianca Azoubel de \\ Instituto da Criança -HC/FMUSP — adna.urbano@hc.fm.usp.br
}

Introdução: a Sala de Espera é um espaço aberto de encontro entre os pares; local onde são expostos os mais diversos sentimentos e compartilhamento de experiências. a troca de saberes se faz de forma natural e instantânea. a abordagem em grupo viabiliza a reflexão coletiva sobre temas pertinentes ao diagnóstico, tratamento, questões culturais e cotidianas dos familiares e pacientes. Objetivos: Proporcionar um espaço coletivo de informação sobre prevenção, promoção e reabilitação à saúde e esclarecer os direitos sociais, rotinas institucionais, questões psíquicas do adoecimento, cuidados no domicílio e adesão ao tratamento. Métodos: As abordagens em Grupo acontecem uma vez por semana no Ambulatório de Onco-Hematologia, com palestras sobre assuntos sugeridos pelos participantes. Após cada palestra é fornecido um questionário de avaliação e sugestão. Os assuntos são preparados pela Equipe Multiprofissional de acordo com as necessidades do Grupo. a prioridade é a consulta e o familiar/ paciente ao ser chamado deverá dirigir-se à consulta podendo retornar após o atendimento. São utilizados vídeos para demonstração, slides, música e filmes. em média 25 participantes frequentam a Sala de Espera. Resultados: no período de janeiro a dezembro de 2013 foram realizados 39 encontros. Os assuntos mais sugeridos foram em relação às orientações médicas; alimentação; aspectos psíquicos/emocionais e direitos sociais. o grau de satisfação foi Bom, pois atingiu $90 \%$. em decorrência dos encontros houve uma demanda importante nos atendimentos com Equipe multiprofissional possibilitando a aproximação entre os familiares e profissionais. na Sala de Espera observa-se que os participantes ficam à vontade para perguntar e esclarecer suas dúvidas, diferente no consultório que a relação às vezes é mais tímida. a informação permite que o indivíduo adquira autonomia para acessar os serviços e seus direitos provocando mudança de comportamento e isso tem um impacto na recuperação do paciente. "... aprendemos bastante coisa na Sala de Espera", “... explica bastante coisa, dúvidas que eu tinha foram tiradas"; ... e o posto de saúde nem sabia...." Conclusão: Lidar com o sofrimento do outro é sem dúvida uma prática que vai além da tecnologia. É escutar sem preconceitos preconcebidos, mas com o saber qualificado. o Grupo Sala de Espera possibilita aprender a partir do cotidiano vivido. na percepção dos profissionais é uma experiência que estimula a continuar com o trabalho, pois os resultados são significativos no processo de promoção, prevenção e reabilitação do paciente. Palavras chaves: Sala de Espera, autonomia e informação.

Urbano, Adna Santos; Monteiro, Rita Mara da Cruz; Cristófani, Lílian Maria; Cury, Marina Rachel Graminha; Nabarrete, Juliana Moura; Andrade, Bianca Azoubel de. Sala de Espera: uma Experiência no Serviço de Onco-Hematologia Pediátrica. In: Anais do Congresso Internacional de Humanidades \& Humanização em Saúde [= Blucher Medical Proceedings, num.2, vol.1]. São Paulo: Editora Blucher, 2014. ISSN 2357-7282 DOI 10.5151/medpro-cihhs-10432 